\title{
Relações de gênero nos lugares para a história
}

\section{FARGE, Arlette. Lugares para a história. Belo Horizonte: Autêntica, 2015.}

\author{
Dulceli de Lourdes Tonet Estacheski*
}

Uma das características dos estudos de gênero é a pluralidade teórica, metodológica e temática. São diversas possibilidades reflexivas que refletem a própria essência de tais estudos, que visam não apenas produções acadêmicas consistentes, mas principalmente, objetivam reflexões que possibilitem transformações nas práticas sociais. $O$ intuito é a construção de um mundo mais justo que, como os estudos de gênero, valorize a diversidade. Teorias e metodologias diversas para pensar práticas diversas de pessoas diversas, essa é a essência.

Arlette Farge é uma historiadora francesa que se dedica aos estudos do século XVIII. No Brasil temos duas de suas importantes obras publicadas, o primeiro, 'O sabor do arquivo', de $2009^{1}$ é uma escrita quase poética sobre a pesquisa arquivística. Trata do contato com o documento, do encantamento pela descoberta na pesquisa histórica que utiliza como fontes os documentos judiciais. Pessoas, queixas, delinquência, vigilância, controle, narrativas, são elementos que constituem tais documentos e revelam histórias, costumes, o cotidiano de pessoas que não queriam suas vidas expostas de tal forma, mas que por terem sido assim documentadas, ajudam a pensar sobre as relações de poder. Os arquivos judiciários expressam os ajustes e os impasses nas relações do sujeito com seu grupo social e com os poderes estabelecidos. E quando pensamos em relações de poder, pensamos em gênero, que "é um primeiro modo de dar significado"2 a elas e, mesmo que a autora não cite especificamente o termo, ela salienta que as mulheres são encontradas nesses arquivos que, para ela, desvendam também "o funcionamento do confronto do masculino e do feminino". A segunda obra, mais recente, publicada em 2015, é 'Lugares

\footnotetext{
* Doutoranda em História pela UFSC. Professora do curso de História da UNESPAR, campus de União da Vitória. E-mail: dulce_tonet@yahoo.com.br

${ }^{1}$ FARGE, Arlette. 0 sabor do arquivo. São Paulo: EDUSP, 2009.

${ }^{2}$ SCOTT, Joan. Gênero uma categoria útil para análise histórica. Educação e realidade. Porto Alegre. Vol. 20. N. 2. Jul/dez, 1995. p. 14.
}

${ }^{3}$ FARGE, op. cit., p. 43. 
para a História'4 e novamente ela não escreve especificamente sobre gênero, mas então, como sua obra pode ser importante para as pesquisas na área? Afinal, de que ela trata?

Em sua introdução Farge ressalta que a historiografia precisa ocupar-se de escritas que interessem à comunidade social e que confrontem o passado e o presente. Quando pesquisamos as relações hierárquicas de gênero por uma perspectiva histórica, é isso que fazemos, é o que queremos, confrontar o passado, as formas como foram constituídas essas relações para melhor argumentar em nossas problematizações em relação ao presente. As questões de gênero são essenciais para a comunidade social e por isso devem ser escritas, lidas e refletidas.

Em sete capítulos a autora apresenta o que chama de 'lugares para história', que são situações que encontram eco na atualidade, como o sofrimento, a violência e a guerra, ou que consideram sujeitos e experiências singulares, como a fala, o acontecimento, a opinião e a diferença dos sexos. Para ela

Esses dois conjuntos se religam pela presença hoje de configurações sociais
violentas e sofridas, e de dificuldades sociais que desqualificam o conjunto das
relações entre o um e o coletivo, entre o homem e a mulher, o ser singular e
sua - ou suas - comunidade social, entre o separado e sua história. ${ }^{5}$

No primeiro capítulo, 'Do sofrimento', Farge questiona se a historiografia pode dar conta do sofrimento humano. O sofrer pode ser um tema para a história ou o sofrimento um lugar para ela? A história tem dado conta de grandes "catástrofes humanas" fazendo com que a dor que elas causam nos sujeitos seja pensada como se fosse apenas fatalidade, consequência de eventos maiores que merecem a total atenção. Dificilmente a história se volta para os "ditos do sofrimento", para as palavras de dor, à exceção, como aponta a autora, da história do tempo presente que valoriza os relatos de pessoas que vivenciaram momentos históricos tensos e apresentam as suas percepções sobre eles. Um bom exemplo disso é o texto de Wollf ${ }^{6}$ que analisa relatos de familiares de desaparecidos políticos da América Latina, evidenciando que os apelos aos sentimentos da opinião pública foram utilizados para fins políticos, para desacreditar regimes militares e fortalecer a luta por direitos humanos.

\footnotetext{
${ }^{4}$ FARGE, Arlette. Lugares para a história. Belo Horizonte: Autêntica, 2015.

${ }^{5}$ FARGE, Lugares... Op. cit. p. 9-10.

${ }^{6}$ WOLFF, Cristina Scheibe. Pedaços da alma: emoções e gênero nos discursos da resistência. Revista Estudos Feministas. Florianópolis, 23(3), setembro/dezembro, 2015.
} 
Para Farge é possível e preciso entender que "a dor significa, e a maneira como a sociedade a capta ou a reusa é extremamente importante".7 Os grandes eventos como guerras e revoluções afetam a vida das pessoas de formas muito distintas, dependendo do lugar social que elas ocupam. Farge salienta a necessidade de se pensar na tristeza de mulheres que sofrem em um mundo caracteristicamente masculino e de pobres que vivem em sociedades tão desiguais. Ela enfatiza que há racionalidade nessas distorções, nessas diferenciações que causam dor e pesquisar sobre isso, escrever a partir desse entendimento, é uma forma de buscar erradicar o sofrimento dos que hoje são atingidos pelos ecos dessas situações históricas. Para Wolff ${ }^{8}$ emoções e gênero se entrelaçam, pois fazem parte da experiência humana. É sobre essa experiência, essencialmente a que causa sofrimento, que Farge nos convida a escrever e é por isso que sua obra é tão importante para pensar as relações de gênero. A racionalização do sofrimento nessas relações sendo historicamente analisados pode explicar os dispositivos que fizeram surgir tais sentimentos e práticas, podendo "fornecer os meios intelectuais de suprimi-los ou de evitá-los"

Há uma insatisfação em relação aos discursos históricos sobre a violência. "A interpretação histórica da violência, dos massacres passados, dos conflitos e das crueldades, praticamente não permite, na hora atual, 'captar' em sua desorientadora atualidade o que se passa sob nossos olhos" ${ }^{10}$. Em seu capítulo 'Da violência', a autora convida a não nos dobrarmos ao sentimento de fatalidade ou impotência diante da violência e ressalta que é legítimo buscar outras interpretações históricas, como o fazem as pesquisas sobre as emoções que destacam sujeitos, gestos e falas. Para ela, a historiografia pode, não apenas, apresentar o conhecimento, mas indicar caminhos para a luta, para o enfrentamento à violência.

A violência tem racionalidade. A violência de gênero é pautada numa racionalidade em relação a uma sociedade hierarquizada na qual homens devem ser dominadores e mulheres submissas, contrariar essa lógica pode levar ao ato violento. Entender a racionalidade da violência, para Farge, é um caminho para evitá-la, transformando a realidade com outras formas de racionalização.

\footnotetext{
${ }^{7}$ Ibidem. p. 19.

${ }^{8}$ WOLFF, op. cit.

${ }^{9}$ FARGE, Lugares... Op. cit., p. 23.

${ }^{10}$ Ibidem. p. 25.
} 
'Da guerra' problematiza a ideia de que a guerra é inevitável e questiona a "estranha disposição que nos fez considerar esse fenômeno como normal"11. No capítulo seguinte, 'Da fala', Farge afirma que o/a historiador/a dá sentido à fala para que o passado se torne inteligível ao leitor e alerta para o fato de que "a história pode ser dita rápido demais"12 e dessa forma invisibilizar as pessoas que a fazem. A escrita da história pode dar lugar aos sujeitos, como Foucault o fez em 'A vida dos homens infames' ${ }^{13}$ ou em 'Eu, Pierre Riviere...' ${ }^{14}$, como Davis fez com Martin Guerre ${ }^{15}$, Esteves com as 'meninas perdidas' ${ }^{16} \mathrm{e}$ Wolff com as mães de desaparecidos políticos ${ }^{17}$.

A história pode pensar a resistência pelas vozes de quem transgride a ordem. Estas percepções são apresentadas nos capítulos seguintes, 'Do acontecimento' e 'Da opinião'. Em seguida, a autora dedica um capítulo para pensar a 'diferença dos sexos' como um lugar para a história. Como salientado acima, Farge não parte dos estudos de gênero, então não se ocupa em pensar as categorias de análise sexo e gênero e suas problematizações. Ela parte de discussões propostas por uma história das mulheres da França, para acusá-la de pessimista, marcada por uma inércia que apresenta as diferenças entre homens e mulheres como algo estável, não tendo como intuito mover o leitor a pensar a necessidade de mudança. A autora critica, assim como o fazem os estudos de gênero, esse caráter fixo das coisas. A ordem hierárquica, desigual, deve ser pensada pelas transgressões que sofre, pois "reconstituir os momentos em que a instabilidade, o desequilíbrio, as recusas" ${ }^{18}$, ocorrem pode demonstrar a possibilidade de novas estruturas.

Farge conclui que "buscando conhecer outro tempo, não escapamos do nosso, e, se este último, como o faz hoje, se arranca brutalmente do passado, a história se engaja também nessa 'realidade' para encontrar seu sentido". ${ }^{19}$ Ao propor uma reflexão histórica que dê conta das dores humanas, sem

\footnotetext{
${ }^{11}$ Ibidem. p. 43.

${ }^{12}$ FARGE, Lugares... Op. cit., p. 61.

${ }^{13}$ FOUCAULT, Michel. A vida dos homens infames. In: Ditos e escritos. Rio de Janeiro: Forense universitária, 2006.

${ }^{14}$ FOUCAULT, Michel. Eu, Pierre Riviere, que degolei minha mãe, minha irmã e meu irmão. Rio de Janeiro: Graal, 1977.

${ }^{15}$ DAVIS, Natalie Zemon. O retorno de Martin Guerre. Rio de Janeiro: Paz e Terra, 1987.

${ }^{16}$ ESTEVES, Martha de Abreu. Meninas Perdidas: Os populares e o cotidiano do amor no Rio de Janeiro da Belle Époque. Rio de Janeiro: Paz e Terra, 1989.

${ }^{17}$ WOLFF, op. cit.

${ }^{18}$ FARGE, Lugares... Op. cit., p. 114.

${ }^{19}$ Ibidem, p. 129.
} 
entendê-las apenas como fatalidades, mas embrenhando-se pelo que move as ações, os sentimentos, as inquietações e os desejos, que transformam as pessoas, fazem sofrer ou lutar, submeter-se ou transgredir, 'Lugares para História' ajuda a pensar a categoria gênero como essencial para as reflexões históricas, mesmo que não a cite. Os estudos de gênero possibilitam compreensões que podem gerar mudança social, que se configuram em uma história engajada, como almeja a autora.

Nota de leitura recebida para publicação em 28/08/2016

Nota de leitura aprovada para publicação em 11/10/2016 